\title{
Las acuarelas de Sverre Fehn: hacia la abstracción arquitectónica del paisaje de Hvasser
}

\author{
Iván I. Rincón Borrego \\ Universidad de Valladolid \\ ivanr@tap.uva.es
}

RESUMEN: El Premio Pritzker de Arquitectura de 1997 fue a parar a las manos de un dibujante enmascarado bajo la piel de un arquitecto, Sverre Fehn. La presente investigación analiza las acuarelas originales que realiza durante décadas en la isla de Hvasser. Desentraña el acervo cultural plasmado en ellas, así como el proceso de abstracción que representan. Las ideas y referencias culturales que emanan de ellas van del Romanticismo al Expresionismo Abstracto, subrayan su importancia como parte consustancial del proceso creativo que deviene en la arquitectura de Sverre Fehn. Este proceso está íntimamente ligado a la figura inspiradora del barco como referente fundamental de su arquitectura.

PALABRAS CLAVE: Sverre Fehn, Hvasser, Acuarela, Abstracción, Barco, Horizonte, Siglo XX.

\section{Watercolours of Sverre Fehn: Toward the Architectural Abstraction of Hvasser's Landscape}

ABSTRACT: The Pritzker Architecture Prize 1997 was won by a draftsman masked under the skin of an architect, Sverre Fehn. This research analyzes his original watercolors done for decades on the island of Hvasser. This research unravels the cultural heritage embodied in them, as well as the process of abstraction that they represent. Ideas and cultural references found in them range from Romanticism to Abstract Expressionism. Their importance as an inherent part of the creative process of Sverre Fehn's architecture is stressed. This process is closely linked to the inspirational figure of the ship.

KEYWORDS: Sverre Fehn, Hvasser, Watercolour, Abstraction, Sailing Ship, Horizon, $20^{\text {th }}$ Century.

Recibido: 14 de abril de 2016 / Aceptado: 1 de agosto de 2016.

\section{La constancia del dibujo}

El Premio Pritzker de Arquitectura de 1997 fue a parar a manos de un creador de fábulas y magnífico dibujante enmascarado bajo la piel de un arquitecto. Sverre Fehn (1924-2009) recogió el galardón el 31 de mayo de 1997 en el Museo Guggenheim de Bilbao, con un discurso emocionado y atípico, plagado de referencias a sus dibujos y a un universo creativo personal, el suyo, que le acompañaba desde los años 50.

Luces y sombras se distribuyen por igual en la vida y obra de Sverre Fehn. Como en el clima nórdico, de días de verano interminables y noches de invierno perpetuas, la carrera del arquitecto vive un sinfín de altibajos; momentos de profunda penuria económica unidos a proyectos que le reportan fama mundial. El incipiente éxito obtenido en sus primeros encargos, el Pabellón de Noruega para la Exposición Universal de Burselas, 1958, y el Pabellón de los Países Nórdicos para la Bienal de Venecia, 1962, fue tan intenso como efímero ${ }^{1}$. Durante la década de los 60, su estudio apenas sobrevivió realizando pequeñas casas unifamiliares y concursos de arquitectura que nunca verían la luz. Así se lo confiesa Sverre Fehn a Per Olaf Fjeld, alumno y a la postre colaborador: «Durante un tiempo no tenía nada de dinero [...] Tan sólo tenía el proyecto de la

RINCÓN BORREGO, Iván I.: «Las acuarelas de Sverre Fehn: hacia la abstracción arquitectónica del paisaje de Hvasser», Boletín de Arte, n. ${ }^{\circ} 37$, Departamento de Historia del Arte, Universidad de Málaga, 2016, pp. 175-188, ISSN: 0211-8483. 
casa Schreiner y daba algunas clases, por lo que tampoco podía permitirme disfrutar demasiado de los aplausos. De hecho, cuando empecé el proyecto de la villa en Norrkøping, dormía en mi coche [un Citroën 2CV] para poder visitar el emplazamiento» (Fjeld, 2009: 61). La situación no mejora en los 70. Edificios como el Centro Cívico de Bøler (1962-72) y el Centro Escuela para Niños Sordos en Skådalen (1971-77) resultaron auténticos focos de polémica, más política que arquitectónica, que minaron su reputación². Las dificultades continuadas atenazaron la viabilidad de su estudio, viéndose obligado a prescindir de su modesto patrimonio, especialmente de una pequeña propiedad en la isla de Hvasser donde pasaba los veranos, lugar que se demostrará de enorme importancia para él. Finalmente, instaló el estudio en su propia casa, junto a su esposa Ingrid, que desempeñaba funciones de gestión y contabilidad, y un único delineante. Sólo a finales de los años 90 sería cuando el éxito internacional, motivado por obras como el Museo Arzobispal Hedmark en Hamar (1967-79) y el Museo de los Glaciares de Fjærland (1989-91) le propiciarían el reconocimiento definitivo y en parte, también, el Premio Pritzker de Arquitectura.

Durante todo ese tiempo hay una actividad que Sverre Fehn no deja de cultivar por pequeño que sea el encargo y adversas las circunstancias, el dibujo. Como él mismo nos recuerda: «El dibujo ha sido una de mis pasiones desde niño [...] Hasta el día de hoy sigo dibujando constantemente, es la mejor forma de expresarme» (Fehn, 1997: 211). Desde joven participa con regularidad en sesiones de dibujo al natural en la Escuela de Arquitectura de Oslo (AHO) donde él mismo imparte docencia entre 1971 y 1995, así como en el Colegio de Arquitectos de Oslo Arkitektenes Hus. De hecho, en sus comienzos, es el interés por el dibujo lo que le une a Geir Grung, su primer socio. La práctica se convierte con el tiempo en una actividad metódica, frenética y vital, como atestigua Eva Madshus: "Cada lunes se presentaba con lapiceros azules recién afilados para dibujar junto a sus colegas. La mayor parte del tiempo hacía rápidos bosquejos de modelos que permanecían estáticos un par de minutos, cinco a lo sumo» ${ }^{3}$ (Madshus, 2008: 34). Estos hechos revelan una predisposición natural para asimilar y comprender todo aquello que le rodea dibujándolo.

El ejercicio constante del dibujo y la pintura alimenta el interés de Sverre Fehn por el arte, tanto por las vanguardias de principios del siglo XX, como por el arte de postguerra.
Autores geográficamente próximos a él, como Johan Christian Dahl o Peder Balke, corrientes pictóricas netamente nórdicas como el Romanticismo, y otras más contemporáneas a sus años de formación y práctica docente en la $\mathrm{AHO}$ como el Expresionismo Abstracto y el Land Art ${ }^{4}$, adquieren un valor detectable en su obra. En ese sentido Per Olaf Fjeld, en calidad de alumno aventajado, rememora cómo Sverre Fehn se explicaba de forma cotidiana «sin distinguir la arquitectura del resto de las artes plásticas. Refiriéndose de manera habitual a la obra de Matisse, Picasso, Francis Bacon, Yves Klein, Giacometti y Brancusi» (Fjeld, 2008: 34) diluyendo por ende las fronteras entre el pensamiento arquitectónico y el artístico.

El legado que mejor expresa esta relación entre el vocabulario del arquitecto y el mundo del arte se encuentra en sus acuarelas estivales de la isla de Hvasser. Frente a la popularidad de sus croquis a línea, recogidos en 180 cuadernos de tamaño A5 actualmente depositados en los archivos del Museo Nacional Noruego de Arte, Arquitectura y Diseño, sus acuarelas conforman un dossier dibujístico poco conocido y aún menos publicado 5 . Posiblemente porque en ocasiones el autor terminaba regalándolas a familiares, amigos y colaboradores del estudio, pero sobre todo porque la mayoría, aproximadamente unas 500, muchas firmadas en los años 70, permanecieron en su estudio hasta 2008, año en que pasan a formar parte de los archivos del Museo Nacional. En cualquier caso, el valor de esta serie de obras no ha sido suficientemente destacado siendo a mi juicio de importancia, por cuanto es en la inmediatez de sus trazos donde el autor establece el germen de futuros proyectos y fábulas gráficas como El laberinto o La Tierra como gran museo ${ }^{6}$, las cuales encontramos en su discurso del Premio Pritzker.

\section{Bañistas y veleros}

Desde principios de los años 70, al término de cada semestre en la Escuela de Arquitectura de Oslo, Sverre Fehn descansa varias semanas junto a su familia en la isla de Hvasser $^{7}$, cerca de Tønsberg, donde pasó buena parte de su infancia. Allí prepara las clases del próximo curso, realiza los primeros bocetos de los concursos que le ocupan, y se dedica sobre todo a pintar acuarelas de pequeño formato. Lo 
1. Comparativa entre una acuarela Bañistas en la costa Hvasser (sin fechar) de Sverre Fehn y Desnudo Azul IV (1952) de

Henri Matisse (Fuentes:

Museo Nacional de Arte,

Arquitectura y Diseño de

Oslo. Foto de Iván I. Rincón

Borrego/ESSERS, Volkmar (2006), Henri Matisse 1869-1954. Maestro del color, Taschen, Colonia)
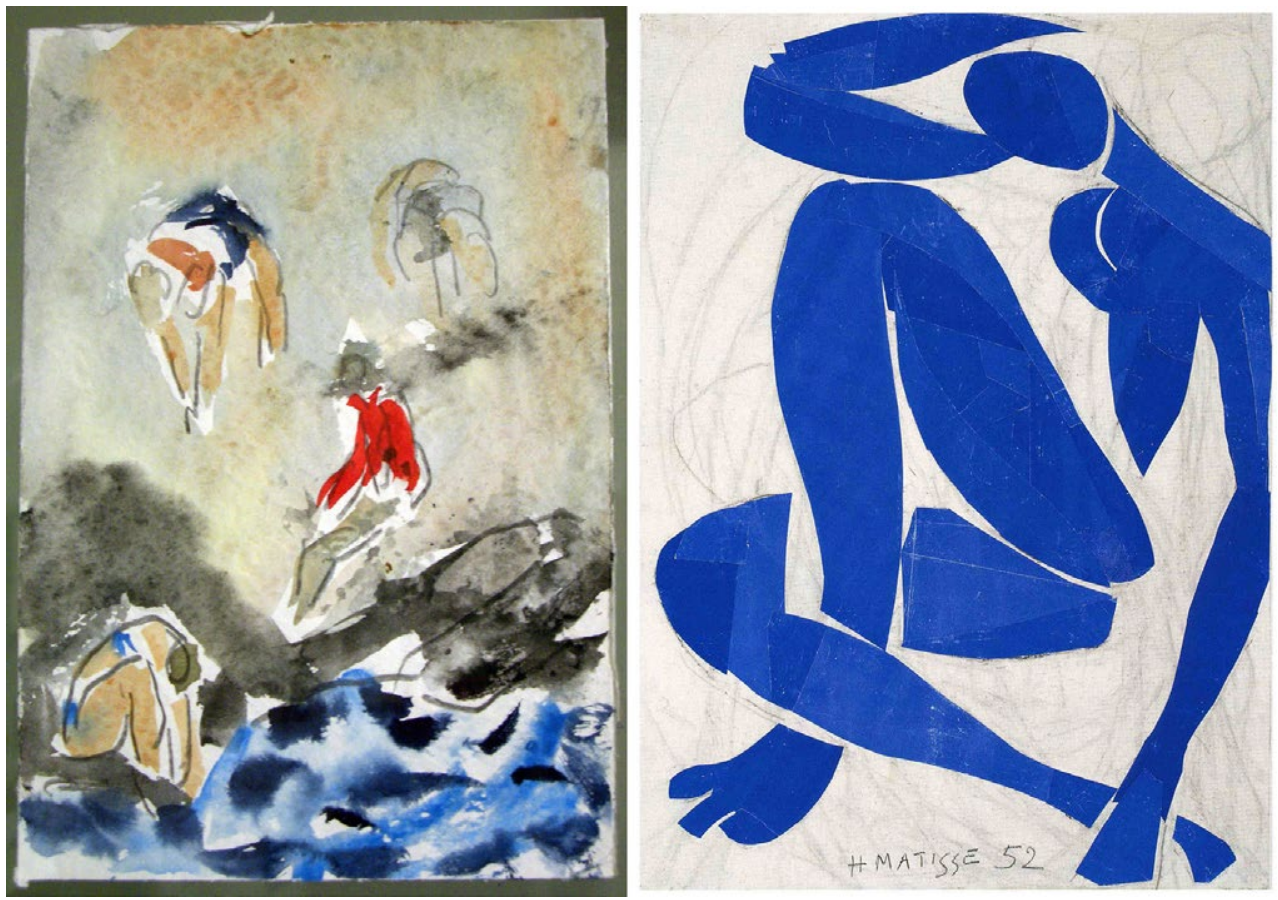

singular es que en cada retiro, de manera constante durante más de una década, retrata los mismos motivos; figuras de bañistas anónimos en la orilla del mar y veleros que surcan el entorno a la isla.

La técnica con que pinta los bañistas se centra en sus figuras recortadas sobre los fondos de roca y agua. Los esbozos captan la forma en que el cuerpo descansa en contacto con las rocas calentadas por el sol, el modo en que las figuras tocan el mar, cómo sobresalen parcialmente sumergidas 0 , simplemente, su salto al agua. Plasma la relación cambiante entre el cuerpo, la materia y el espacio; la forma voluptuosa en que el cuerpo puede adaptarse al granito; la tensión superficial del agua rota por la acción del baño y el espacio que dejan al despegarse del suelo.

Los bañistas son recurrentes en sus acuarelas. É mismo lo dice: "nunca he dejado de dibujar sobre la vida" (Fehn,1992: 45), pero no por ello los considera menos significativos y, en todo caso, relacionados con el arte y la arquitectura. En ese sentido, otras disciplinas como la música y la danza también le seducen por la influencia de su esposa Ingrid, intérprete y pianista de profesión ${ }^{8}$. De hecho, a lo largo de uno de sus cuadernos de 1987 retrata de forma obsesiva a Josephine Baker: «Durante un tiempo la dibujaba de forma constante" surcando rítmicamente el espacio, en imágenes que recuerdan a La danza (1909-10) y La música (1910) de Henri Matisse. Si en las obras del artista francés la relación bidimensional fondo-figura enfatiza la presencia del movimiento, tanto del cuerpo como del aire a su alrededor, que vibra por la acción del sonido en un espacio plano, en los dibujos de Sverre Fehn sucede algo parecido, por la figuración cambiante del espacio gracias al movimiento de los bañistas. Los trazos de las últimas composiciones de papeles recortados de Henri Matisse, como Desnudo Azul IV (1952) [1] son elocuentes en ese mismo sentido. La sombra ausente de los pliegues del cuerpo femenino acurrucado es el blanco en el papel, destacando así no tanto la forma, sino la relación abstracta que se establece entre fondo y figura, entre paisaje y cuerpo.

La misma sensibilidad demostrada por Matisse en obras como Polinesia. El cielo y Polinesia. El mar (1946) es compartida por Sverre Fehn también en sus dibujos a línea. El pintor francés utiliza siluetas de seres vivos de nítidos perfiles blancos sobre un fondo ajedrezado de papeles azul claro y oscuro. Plantas, peces y pájaros se mezclan arabescos entre sí, confundiendo el cielo con el mar en una composición bidimensional que disuelve los límites del horizonte, 


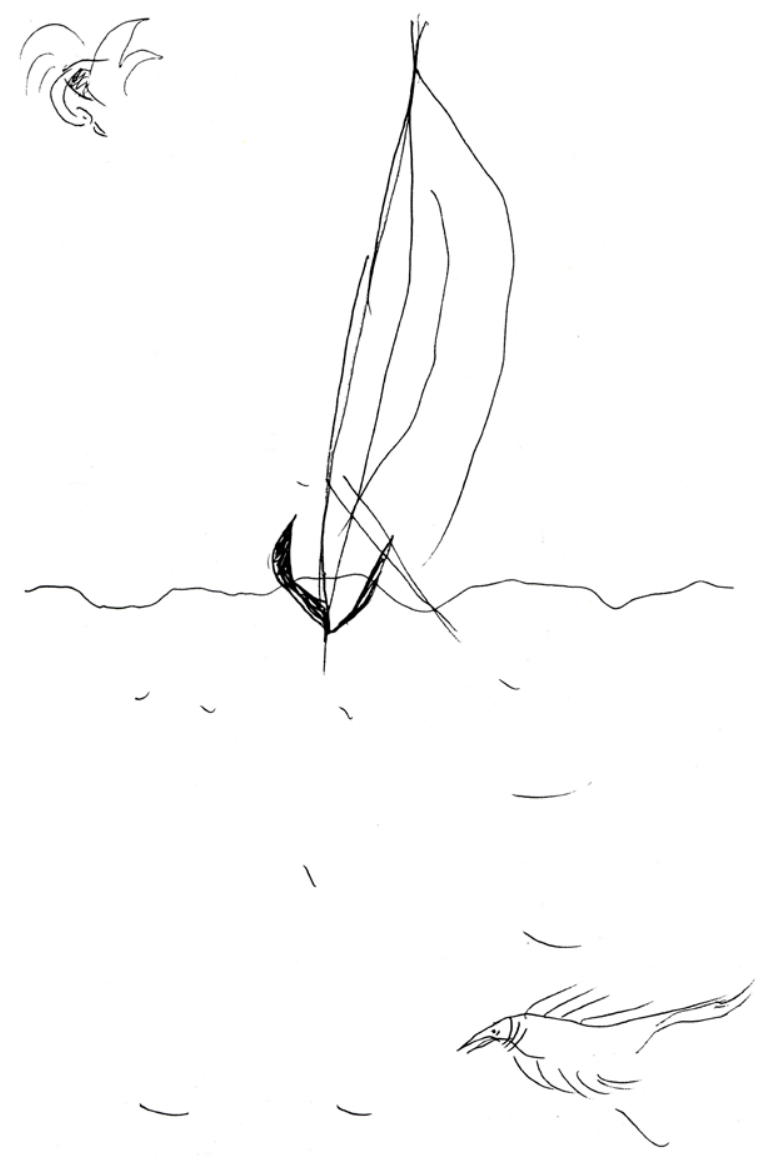

2. Sverre Fehn, Ideograma (sin fechar) (Fuentes: NORRI, Marja-Riitta y KÄRKKäINEL, Maija (ed) (1992), The Poetry of Straight Line: Five Masters of the North, Museum of Finnish Architecture, Helsinki)

el cual pierde su profundidad. Así mismo, en sus croquis Sverre Fehn recurre a una paleta de seres dibujados a línea, árboles, peces y pájaros, acompañados por barcos y arquitecturas, que juegan de manera ambigua sobre una única línea recta en mitad de la cuartilla, un horizonte sin profundidad perspectiva [2].

Por otro lado, el modo en que Sverre Fehn representa el cuerpo en movimiento nos recuerda a la obra de Yves Klein. El artista francés encarna la empatía sostenida entre el cuerpo, el vacío y la materia. En el montaje fotográfico El hombre en el espacio (1960) [5] Klein activa la memoria de uno de los anhelos primordiales del ser humano; ser capaz de volar. En un tiempo, los años 60, en que la carrera espacial permitió superar la atracción gravitatoria de la Tierra y llegar a la Luna, los dibujos del arquitecto se llenan de seres ingrávidos, evocadores de los intereses compartidos con Klein. Desde esa óptica, en tanto que Fehn se refiere a Klein en sus clases, es plausible pensar que igualmente conoce sus Antropometrías de la época azul en las que el cuerpo desnudo de una modelo dejaba una impronta de pintura azul al ritmo de Sinfonía monótona. Dejando de lado la performace, es el resultado plástico lo que interesa al noruego, es decir, la huella que el cuerpo ausente, ingrávido, deja sobre el papel.

Proyectos y edificios construidos por Sverre Fehn, como el Museo del Bosque de Elverum (1965-66) o el Museo Arzobispal Hedmark en Hamar (1967-79) también escenifican la ingravidez de los cuerpos dibujados en sus aguadas mediante el uso de plataformas arquitectónicas que se elevan sobre los estratos, arqueológicos y naturales, de sus respectivos emplazamientos. Las pesadas plataformas de hormigón parecen más ligeras por su continuo movimiento respecto a las cotas del terreno y, por ende, su experiencia acompaña la conciencia de la fuerza de la gravedad y la resistencia del suelo reflejada en el visitante. Ambos museos actúan como estímulo potencial del movimiento gravitatorio, como El hombre en el espacio. La interacción háptica entre el cuerpo humano y la forma construida es inmediata en ellos, y una característica en la obra de Fehn. Cada edificio impele al usuario a un vagar cinestésico, a una coreografía orquestada por la mano del arquitecto, cristalizada en los pasos y puentes de hormigón que accionan los resortes del cuerpo como en un ballet que lo hace levitar de manera simbólica ${ }^{9}$.

Los veleros y su relación con el paisaje son el otro gran tema pictórico para Sverre Fehn. El paisaje costero de Hvasser es diferente y majestuoso. A pocos kilómetros al Este del cabo Verdens Ende, la llamada «punta del fin del mundo", la costa de la isla alterna los imprecisos matices de las brumas verdeazuladas y los oscuros afloramientos rocosos de bordes pulidos. En la distancia, es el tráfico incesante de los navíos que conectan con Oslo el que interrumpe la línea del horizonte. Todos, estímulos que dejan huella en el arquitecto, ya no sólo porque los dibuja de manera insistente, sino también porque los experimenta de un modo atávico. Prueba de ello es su día a día en Hvasser, el cual dista mucho de las comodidades y los ritmos de Oslo. La pequeña casa de vacaciones donde reside es una humilde cabaña de madera que semeja más una casa de pescadores. De 
hecho, él mismo construye los objetos cotidianos y muebles más sencillos de pino, mientras que el resto los encarga a carpinteros locales, en su mayoría, constructores de barcos (Fjeld, 2009: 21). Siente por tanto afinidad hacia el modo de hacer de los viejos oficios, ejemplo en el uso correcto de los materiales y las formas, constructores «inconscientes» que diría Philip Drew (Drew, 1973: 24), en tanto que sus creaciones son parte de una disciplina aprendida a través de la imitación y la corrección. Así las formas artesanales trabajadas con madera son una motivación positiva para él.

Las rutinas veraniegas en Hvasser $^{10}$, el baño, la navegación, los largos paseos en bicicleta y la pintura constituyen un aislamiento saludable que le acerca a un modo más primitivo de aprehender los vínculos entre el lenguaje de la naturaleza y el de las creaciones humanas. Sentir durante un tiempo dilatado las fuerzas que modelan la isla, el paso de los días, el movimiento de las aguas, la superficie de las rocas, el empuje de la brisa marina y poder dibujar los artificios creados por el hombre para confrontar tales fuerzas, le hace más consciente de los fundamentos de un paisaje marítimo de fuerte carga abstracta, proceso en el que sus dibujos de veleros son la clave.

Analizando con detalle los archivos del Museo Nacional es posible rastrear la evolución, año tras año, de los veleros que surcan sus aguadas. Si bien muchas de ellas no se encuentran fechadas ni firmadas, la repetición del tema nos permite analizar su morfología y establecer la hipótesis de una secuencia que cuenta los cambios en su forma de mirar el paisaje que pinta.

Las primeras tintas de veleros de 1976 muestran el protagonismo del barco recortado sobre la superficie del agua. Rápidos trazos de lápiz dibujan el contorno del casco y la frontera de su silueta con el cielo y el mar. Las veladuras inundan el fondo del dibujo, primero el cielo, después las rocas y por último el agua, esquivando la forma del navío, que se presenta como un espacio blanco recortado en medio de la composición. Esta técnica la repite en muchas ocasiones de forma similar, a excepción del color, preferiblemente rojizo, que tiñe la forma del barco [3].

Algunas de las pinturas de 1977 experimentan un cambio significativo pues el velero se aleja. Por una parte, la forma del casco, antes perfectamente definida, se empieza a confundir con el resto del barco, ya no sólo por la distancia, sino porque las velas aparecen desplegadas cobrando
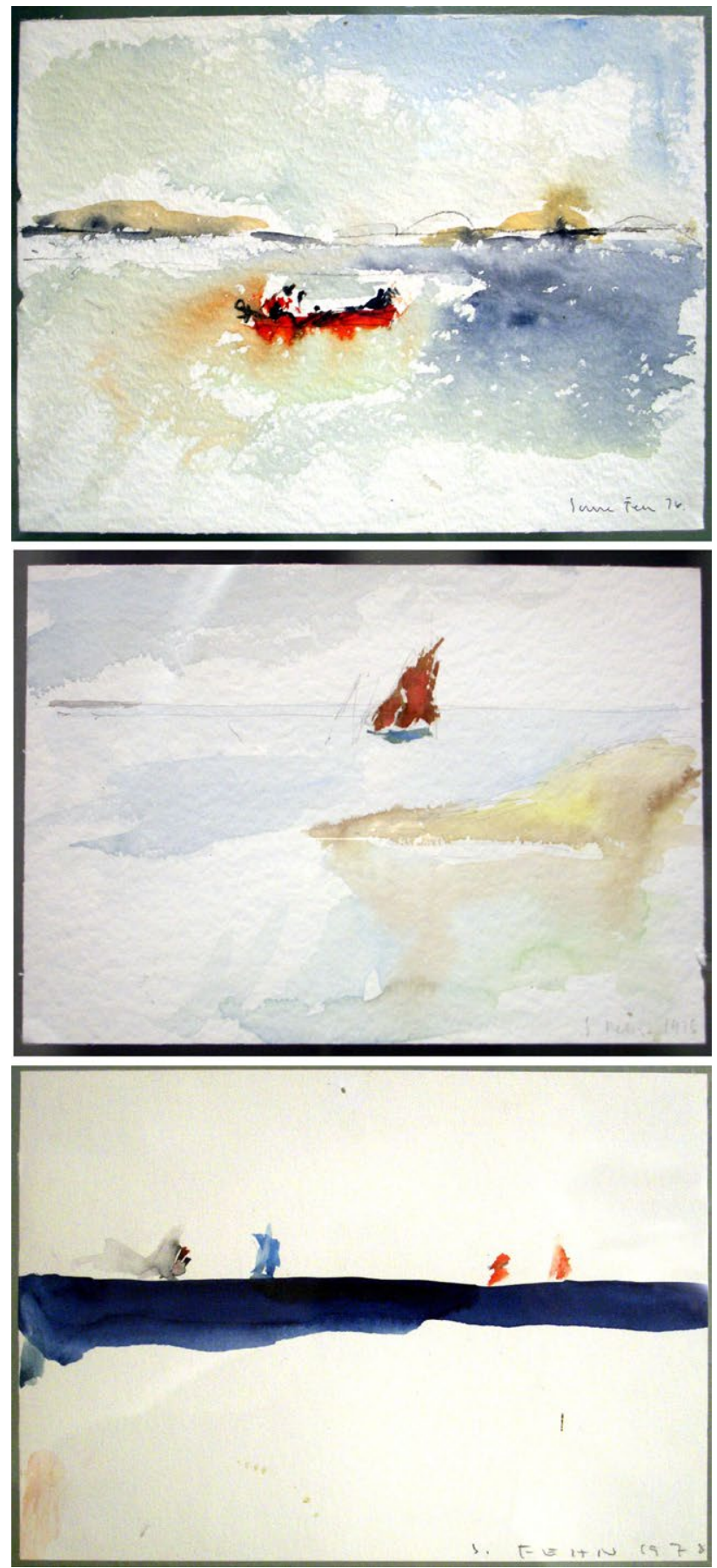

3. Secuencia de acuarelas de veleros en Hvasser realizadas por Sverre Fehn, de 1976 a 1978 (Fuente: Museo Nacional de Arte, Arquitectura y Diseño de Oslo. Foto de Iván I. Rincón Borrego) 


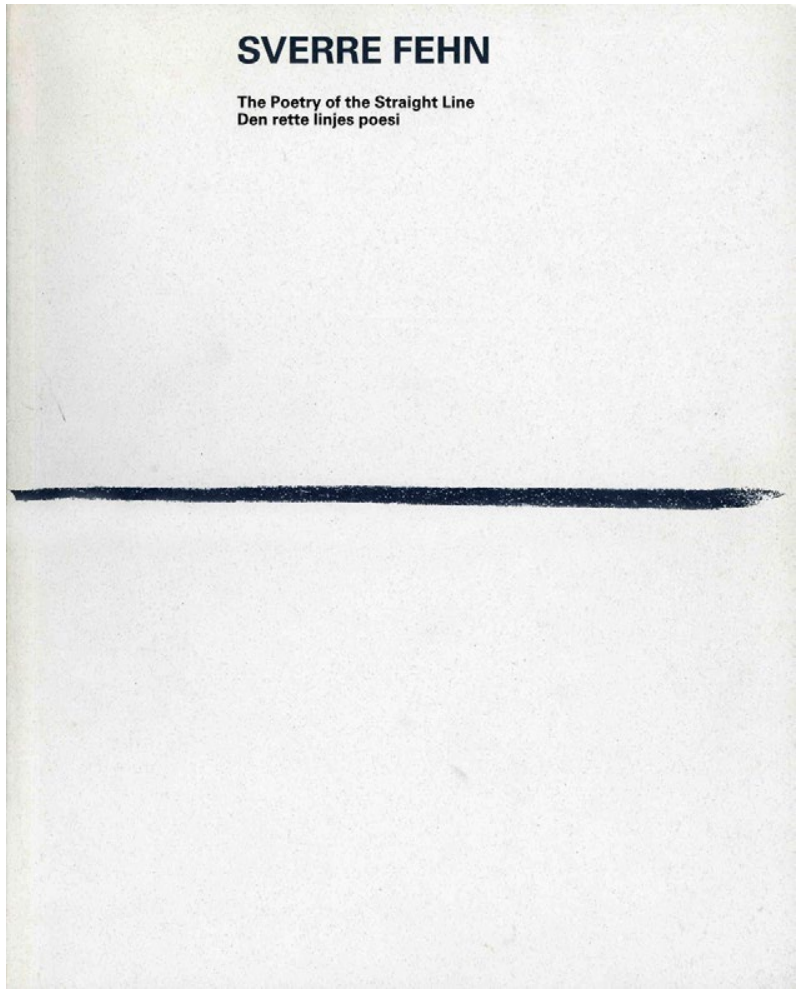

4. Sverre Fehn, portada de The Poetry of Straight Line (1992) (Fuentes: NORRI, Marja-Riitta y KÄRKKÄINEL, Maija ed (1992), The Poetry of Straight Line: Five Masters of the North, Museum of Finnish Architecture, Helsinki)

un mayor protagonismo en la composición. Por otro lado, la embarcación se dibuja a la altura en que el mástil y el velamen puntúan la continuidad del horizonte. Para Fehn, al mismo tiempo que la nave se aleja y disminuye su tamaño, asciende virtualmente hacia el cielo.

Por último, numerosas acuarelas de los veranos de 1978 y 1979, representan una distancia entre el barco y el observador cercana a los límites del ojo humano, próxima al infinito y a la abstracción del paisaje marítimo. El océano ya no inunda el papel, sino que apenas se representa con una mancha enérgica rasgada en medio de la hoja. Sobre ella gravitan pequeñas salpicaduras de color, las velas distantes recortadas sobre el fondo blanco del cielo. El mismo trazo azul ceniza que representa el agua del mar, dibuja con precisión la línea de horizonte, la cual a su vez articula el espacio del paisaje. La presencia de los barcos dotan de dramatismo a la composición, detenidos por el pincel del arquitecto en el instante último antes de desaparecer. Frente al escenario acotado y tranquilizador de sus primeras acuarelas, ahora los horizontes se abren hacia un todo abarcador y una desaparición abrupta en la nada, celebración de imágenes sensibles a la desposesión romántica, a las puertas de una abstracción codificada en un sencillo trazo.

Siguiendo antecedentes, Sverre Fehn dará un último paso en el diseño de la portada de The Poetry of Straight Line: Five Masters of the North (1992) [4]. En la imagen que preside esta publicación ${ }^{11}$, piedra angular en su trayectoria, el barco finalmente ha desaparecido dejando atrás una única línea gruesa horizontal. El gesto no solo codifica el paisaje, sino que también representa toda una declaración intelectual y arquitectónica, pues el título homenajea El poema del ángulo recto de Le Corbusier, texto de referencia para Fehn, que igualmente aborda la intelectualización gráfica del mundo, en ese caso mediante dos ejes cruzados en ángulo recto, uno vertical, antropomórfico, y otro horizontal, paisajístico ${ }^{12}$.

\section{Imaginario pictórico}

A los ojos de Sverre Fehn la representación de un velero sobre el horizonte atesora un fuerte simbolismo pues ilustra imágenes asociadas al paso del tiempo y al conjunto de las grandes empresas humanas. El barco es la respuesta que incita al viaje, como lo es la arquitectura a la audacia.

Las singladuras dibujadas por Fehn representan un reflejo moderno de la pintura romántica en general, y de su corolario abstracto de los años 60, en particular. El modo en que autores como William Turner o John Martin tratan el viaje por mar resulta apocalíptico en la mayoría de las ocasiones, por la devastación de las fuerzas contenidas en la Naturaleza. En El naufragio (1805) o en El barco negrero (1840), por poner sólo dos ejemplos de William Turner, el hombre y sus construcciones sucumben a vertiginosos cataclismos. Por el contrario, Sverre Fehn representa sus veleros envueltos en una tranquilidad de océanos y cielos en calma, si bien, tampoco descarta la posibilidad del hundimiento. De hecho, en muchos de sus dibujos a línea anota reiteradamente: «el barco pertenece al horizonte» junto al croquis de una nave en liza con el mar [5]. En ese sentido, cabe afirmar que el noruego convive con el temperamento contradictorio de la pintura del Romanticismo. Entre lo singular y fecundo del 
doble sentimiento, por un lado de fascinación por las construcciones del ingenio humano, por otro de lucidez y certidumbre ante la desmesurada capacidad destructora de la Naturaleza y el Tiempo.

La influencia de la pintura nórdica en Sverre Fehn se concreta en las obras que anuncian la incipiente abstracción de la naturaleza a través del estudio del horizonte ${ }^{13}$. Autores específicamente noruegos como Johan Christian Dahl, Estudio de nubes con horizonte (1832), o Peder Balke, Paisaje marítimo y pecio (1860), y otros como Frederic Edwin Church, Marina con casquete glaciar a lo lejos (1859), o Georgia O’Keeffe, La luz llega a las Ilanuras II (1917) y Colinas rojas y cielo (1945), destilan la experiencia primigenia del paisaje en imágenes caracterizadas por la división entre lo aéreo y lo telúrico, ascendente ya detectado en los croquis de Sverre Fehn. No obstante, más allá de la constancia de este acervo cultural, por la evolución de sus acuarelas y, sobre todo, por la elocuente portada de The Poetry of Straigth Line, la sensibilidad del arquitecto hacia al advenimiento del universo de la abstracción del horizonte resulta manifiesto. De hecho, desde una perspectiva más amplia, dicha sensibilidad le sitúa en la estela de las teorías de Robert Rosenblum recogidas en La pintura moderna y la tradición del Romanticismo nórdico. De Friedrich a Rothko, que ponen el acento en la supervivencia de argumentos y temas intrínsecamente románticos en la vanguardia norteamericana del Expresionismo Abstracto. Cerrando de ese modo un círculo que explica por qué determinados estudios de paisajes que realiza en los años 80 sitúan al espectador frente campos de color, vacíos donde resuenan los ecos de una naturaleza elemental, comparables a la obra de Rothko [6]. E igualmente, cómo muchos de sus ideogramas a línea evocan la misma acción gravitatoria que impelen las constelaciones simbólicas de Adolph Gottlieb.

Si consideramos las acuarelas de Sverre Fehn como el fruto de una actividad cotidiana, llevada a cabo en soledad de manera casi ritual, la experiencia que comportan está ligada a su forma de mirar y abstraer el paisaje de Hvasser. En sus propias palabras: «La habitación infinita es masa. El ser humano no vive en un espacio articulado entre interior y exterior. La masa siempre nos rodea. Nunca se halla completamente libre de la gran habitación cósmica, no obstante, podemos orientarla mediante la contemplación» (Fehn y Fjeld, 1988: 40), contemplación que antecede al dibujo. Después de todo, ya en la Antigüedad el horizonte,
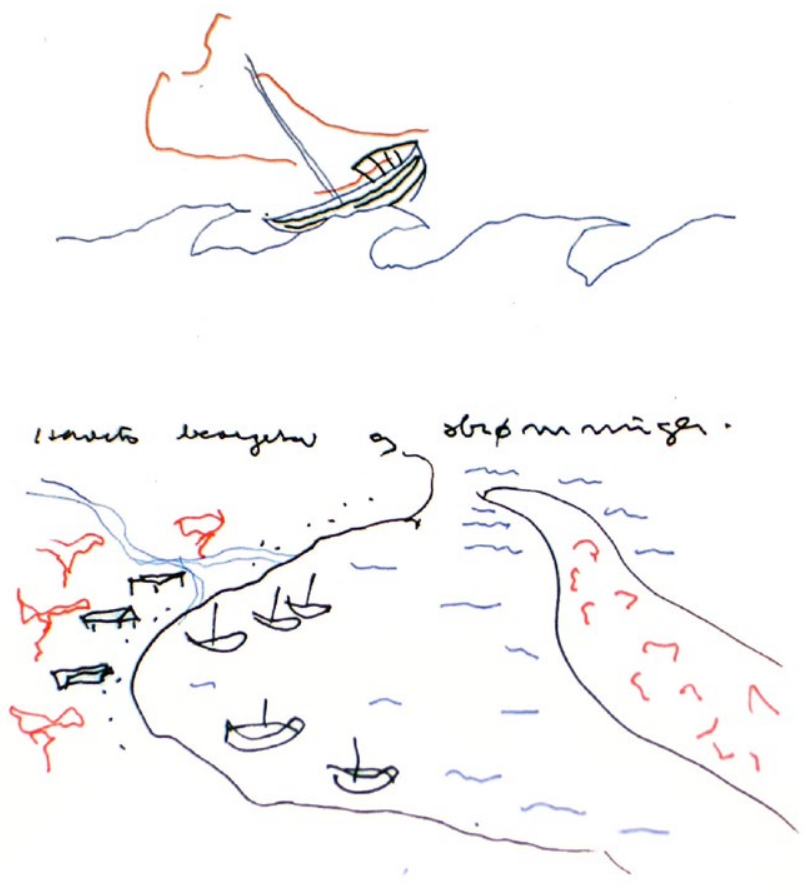

5. Sverre Fehn. Croquis El barco pertenece al horizonte (sin fechar) (Fuente: Museo Nacional de Arte, Arquitectura y Diseño de Oslo. Foto de Iván I. Rincón Borrego)

horismos, es la línea que no interrumpe la mirada, sino a partir del cual ésta comienza a existir.

\section{La arquitectura del barco}

Los veleros de Sverre Fehn simbolizan tanto la perfección del arte constructivo que los posibilita como la fugacidad de su singladura, paradigma aplicable a su arquitectura destinada a lidiar, como el barco, con parajes de gran hostilidad.

Este papel intercambiable entre barco y arquitectura alude a la cultura vikinga, en concreto a las antiguas iglesias stave que eran llevadas a cabo por maestros carpinteros y ebanistas navales ${ }^{14}$, como nos explica Fehn: «Aquellos carpinteros [vikingos] trabajaban las construcciones de madera como barcos. Con las iglesias stave, los pilares no se hunden en la tierra. Las columnas se posan en el terreno y se atan en su coronación. Pienso en las velas y en lo que sucede en un barco, y es el mismo sistema» (Fehn, 1994: 24). En ese 

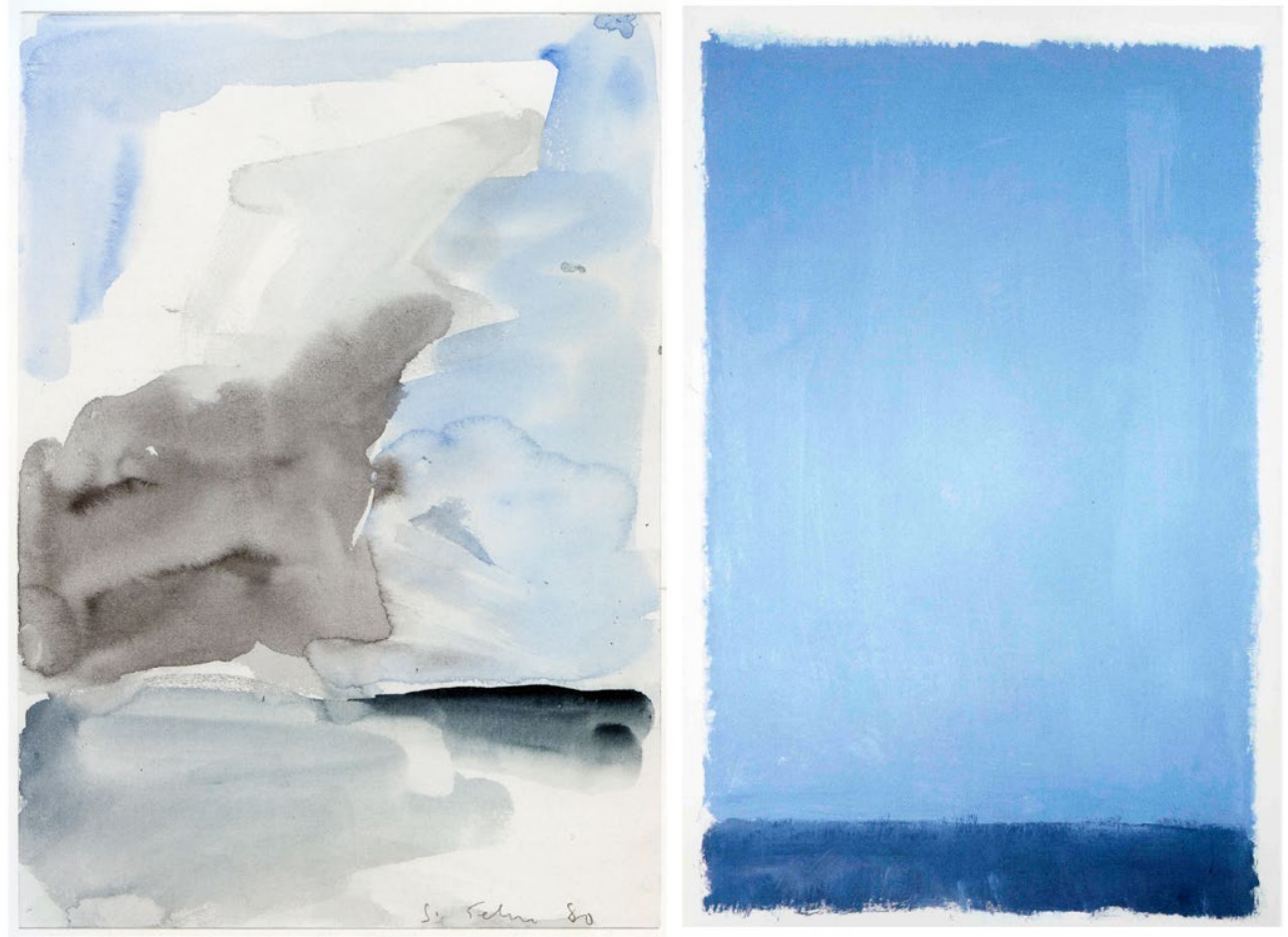

6. Comparativa entre Estudio de paisaje (1980) de Sverre Fehn y una obra de Mark Rothko, Sin título (1969) (Fuentes: Museo Nacional de Arte, Arquitectura y Diseño de Oslo. Foto de Iván I. Rincón Borrego/AAVV (2007), La abstracción del paisaje. Del romanticismo nórdico al expresionismo abstracto. In memoriam Robert Rosemblum (1927-2006), Fundación Juan March, Madrid)

sentido, el valor atávico de los oficios vuelve a ser de importancia para él a la hora de pensar y construir su arquitectura ${ }^{15}$. Talante que a su vez ya había manifestado uno de sus maestros de la Escuela de Artes y Oficios de Oslo, Knut Knutsen, cuando en el célebre artículo «People in Focus» publicado en Byggekunst en 1961 escribe: «Podemos aprender enormemente de la concisión, la estricta necesidad y el énfasis funcional de la disposición en planta de un barco» (Knutsen, 2008: 249).

Sverre Fehn considera que el velero y la arquitectura comparten la escala que da el correcto uso de la madera, no obstante, a su juicio el barco antecede a la arquitectura, por cuanto le sirve de inspiración a ésta: «La gran empresa nació, no en el arte de la construcción de edificios, que pertenece a la tierra, sino en la construcción de barcos [...] El mástil es la construcción que, junto con las velas, mejor ha significado la captura del viento y le ha dado al hombre [el conocimiento de] el globo entero» (Fehn, 1992: 34). A dife- rencia de Knut Knutsen, Sverre Fehn no sólo considerará la planta del barco como modelo, sino sobre todo la sección y su estructura de madera, de quillas, mástiles y cuadernas que construyen la forma ahusada. Su admiración se deja sentir durante la conferencia que imparte en 1994 en el MIT: "en la sección de un barco vikingo se pueden sentir los árboles pues carece de líneas rectas. Con esas naves, con ese tipo de construcciones, los vikingos alcanzaron el horizonte y lo desconocido» (Fehn, 1994: 23). Sus insistentes aguadas de veleros, también lo atestiguan.

A medida que Sverre Fehn dibuja embarcaciones intuye el espacio de la arquitectura y viceversa ${ }^{16}$. A lo largo de su trayectoria son continuos los proyectos enraizados en una interpretación, que no mímesis, del barco como referente de sus proyectos, especialmente de los barcos vikingos recuperados a finales del siglo $\mathrm{XIX}^{17}$.

En 1978, año del que datan muchas de las acuarelas de Hvasser, Fehn ya experimenta con estructuras de peque- 
ña escala análogas al casco de una nave vikinga para proteger las valiosas inscripciones prehistóricas de Svartskogen, al sur de Noruega [7]. Un año después, en el proyecto para el Museo Minero de Røros (1979-80) [8] depura dicha analogía. Proyecta un edificio-puente para conectar ambas orillas del río Glåmma a su paso por Røros, como hacían las antiguas pasarelas de esta localidad minera llevando el mineral de los altos hornos a las pilas de impurezas amontonadas en la otra margen. Si a primera vista el museo adolece de evidentes rasgos biomórficos, llama más la atención el cuidado con que se proyectan las costillas estructurales que vertebran su forma volada, advirtiendo que se trata de un complejo artefacto poético, la analogía estructural de la sección de una nave vikinga.

El esqueleto del edificio-puente se halla suspendido de una única viga de hormigón en $T$ invertida que descansa sobre dos machones situados a ambos lados del cauce fluvial. Sobre el eje vertical de esta sólida estructura a modo de quilla, se apoyan finos pares y tornapuntas que soportan los faldones inclinados de cubierta, como si del casco de una nave invertida se tratase. La condición de edificio-puente incrementa la sensación de ingravidez provocada en el visitante, pues el conjunto parece surcar el aire con la misma ligereza que los veleros el agua. En la piel de un armador atento con precisión a las dimensiones, es la distancia entre ambas orillas y la cualidad de los materiales, hormigón en masa y escuadrías de madera, lo que le guía en el diseño de la elocuente estructura: puente y barco al mismo tiempo. El edificio sustituye la resistencia del agua por la de la gravedad, y salva la depresión del curso fluvial resistiendo apoyado por la proa y popa sobre los márgenes de la ribera.

El proyecto de la iglesia de Honningsvåg (1965) [9] no es menos significativo con respecto a la impronta que los navíos de Hvasser dejan en la arquitectura de Fehn. Ahora es la forma del mástil la que entra en juego, el elemento que

8. Sverre Fehn, vista en planta y alzado de la maqueta del Museo Minero de Røros (1979-80) (Fuentes: FJELD, Per Olaf (2009), Sverre Fehn: the pattern of thoughts, The Monacelli Press, New York)
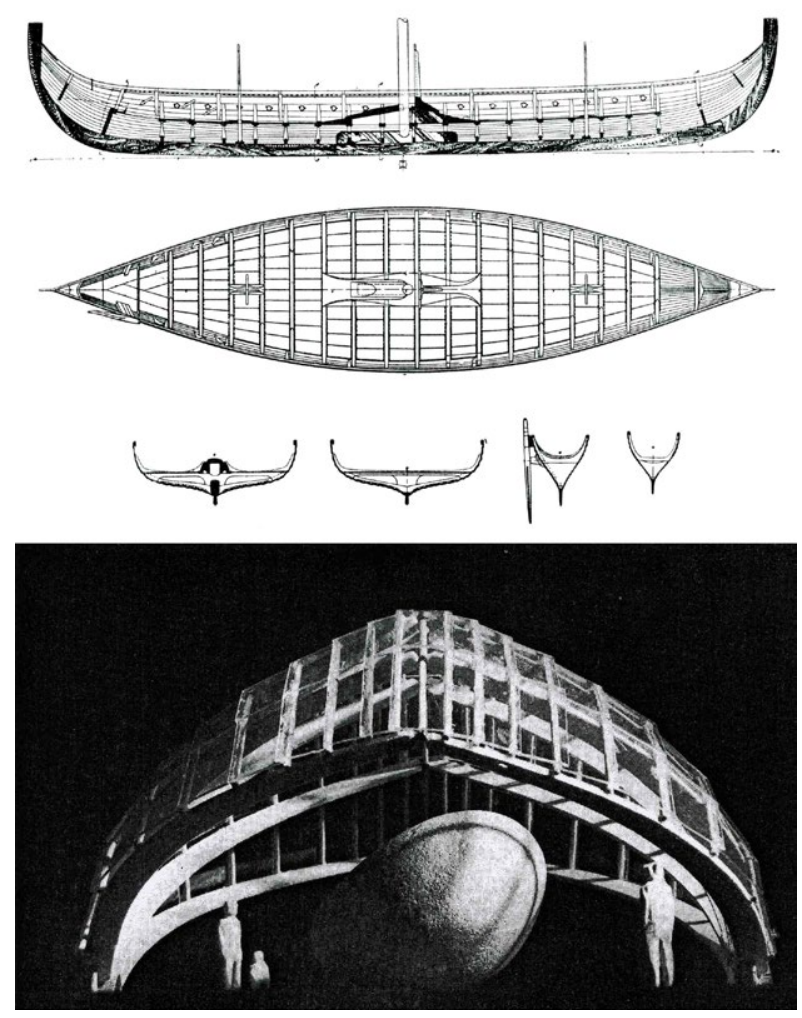

7. Planta y secciones del barco vikingo Gokstad (h. 850) comparadas con el proyecto de cubierta para las ruinas de Svartskogen (1978) de Sverre Fehn (Fuentes: BUGGE, Gunnar y NORBERG SCHULZ, Christian (1990), Stav Og Laft. Norsk Arkiteturforlag, Oslo/NORBERG SCHULZ, Christian y POSTIGLIONE, Gennaro (1997), Sverre Fehn: Works, Projects, Writings, 1949-1996, The Monacelli Press, Milan)

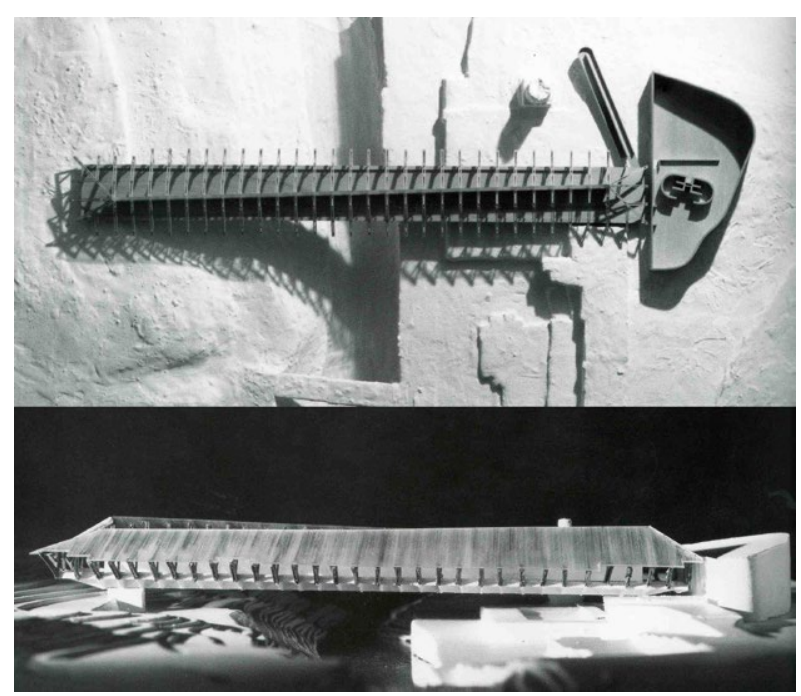



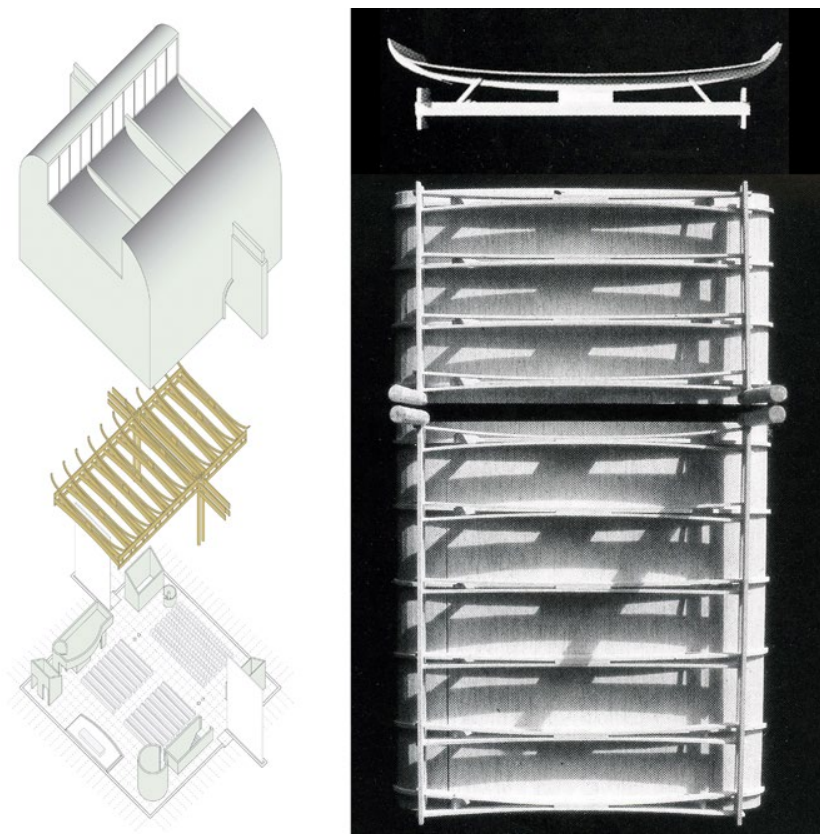

9. Axonometría del proyecto de la iglesia de Honningsvåg (1965), comparada la maqueta de la estructura de madera del mismo edificio en planta y sección realizada por Sverre Fehn (Fuentes: Dibujo de Iván I. Rincón Borrego/NORBERG SCHULZ, Christian y POSTIGLIONE, Gennaro (1997), Sverre Fehn: Works, Projects, Writings, 1949-1996, The Monacelli Press, Milán)

une tierra y mar, pilar y árbol. La iglesia se emplaza sobre la cima del Cabo Norte mediante un volumen de hormigón de aspecto monolítico que se protege del castigo de los vientos. Las maquetas proyectadas por Fehn trabajan con la implantación como itinerario procesional de acceso al conjunto. Primero se descubre la verticalidad del bloque de hormigón y el mástil de la cruz en lo alto, luego la panorámica del paisaje y finalmente el acceso en forma de doble arco, único resquicio para entrar al misterioso templo, cuyo aspecto desde fuera es casi impenetrable. En su interior, protegido de las inclemencias, se encuentra un armazón de madera de gran delicadeza y sofisticación formal. Dos parejas de pies derechos de pino noruego se alzan vertiginosos para soportar un conjunto de diez pares de vigas curvas que descansan sobre zoquetes y correas, evocando la superficie curva de un casco en construcción ${ }^{18}$ suspendido de la luz que se filtra a través de los lucernarios de cubierta.

El proyecto certifica la empatía de Sverre Fehn hacia los lobos de mar, posiblemente adquirida durante la práctica de la navegación en Hvasser, sentimiento que se descubre cuando relata las intenciones pretendidas con su diseño: «Al construir una iglesia para una población como Honningsvåg, cuya supervivencia depende de la pesca, la tendencia a pensar en la madera y los mástiles de los barcos es algo natural. Si un marinero encuentra las curvas del edificio semejantes a las del casco de su nave, o si al acercarse a un pilar se da cuenta de que tiene las mismas dimensiones que un mástil, el espacio se le presenta cercano y familiar, repleto de símbolos cotidianos» (Norberg Schulz y Postiglione, 1997: 113) Ecos de formas navales que resuenan en las formas del edificio sacro y le ayudan a desempeñar su función simbólica, la de ofrecer cobijo espiritual a los habitantes de Honningsvåg y encontrar en el espacio arquitectónico la tranquilidad para comprender el mundo, el suyo propio, ligado al mar, en un interior que los protege. Tales símbolos, asociados a ese emplazamiento concreto del Cabo Norte, se vuelven además intrínsecamente poéticos porque convierten al edificio en un cauce de expresión que trasciende la mera semejanza estructural, y lo acercan a la idea de metáfora arquitectónica.

Por último, el proyecto del Museo Wasa (1982) [10] constituye sin duda una de las referencias navales de mayor calado en la obra de Sverre Fehn. Tomando como punto de partida su fábula La Tierra como gran museo, anteriormente mencionada, proyecta un edificio que se hunde en el lecho del estuario de Estocolmo para albergar el Wasa, un buque de guerra hundido descubierto en los años $60^{19}$. Propone mostrar el pecio en el interior de un dique excavado bajo el parque aledaño al Museo Nórdico de Estocolmo, para devolverlo simbólicamente a su emplazamiento original bajo las aguas $^{20}$. Su propuesta es trazar una larga trinchera que atraviese el jardín hundiéndose progresivamente en la corteza de la tierra hasta conducir al visitante a la sala donde se aloja el Wasa, en mitad de un descomunal vacío prismático cerrado por muros de hormigón y cubierto por arcos fajones que permiten el paso de la luz tamizada por el parque.

De forma análoga al Museo Arzobispal de Hamar, el interior del Museo Wasa se articula mediante pasarelas y rampas de hormigón entrecruzadas con la arboladura y el velamen que descienden hasta desembarcar a los pies de la quilla, yendo de lo más aéreo a lo más pesado. Dicho itinerario conduce al visitante de la luminosidad del parque a las profundidades bajo la nave. El museo excavado recrea por tanto la conciencia del instante del naufragio, protagonizado 
metafóricamente por el usuario como si fuera el suyo propio, experimentado a través de la arquitectura subterránea y del descenso figurado de su cuerpo hacia un fondo frío y cavernoso, donde se detuvo el tiempo ${ }^{21}$.

A semejanza de cómo el Wasa se hundió en el mar, Fehn hunde el museo en la Tierra. Su arquitectura constituye una analogía del acontecimiento y el registro de la memoria del emblemático navío.

\section{Conclusiones}

Las acuarelas que realiza Sverre Fehn en la isla de Hvasser, como sus ideogramas, se encuentran en el núcleo de la relación iniciática y vital que el arquitecto establece entre dibujo y construcción. Cabe recordar que en 1994, cinco años después de la muerte de Geir Grung, Fehn dice de su amigo que «el pilar de su disciplina arquitectónica y su sensibilidad constructiva procede de su constante práctica del dibujo del natural» (Madshus, 2008). Precisamente la práctica que él mismo nunca abandonó ni en la más difícil de las circunstancias.

Las reiteradas estancias en Hvasser, sus rutinas y sencillo modo de vida le otorgan una conciencia casi primitiva de todo aquello que rodea la vida en la la isla, conciencia que explica su manera sintética de dibujar el mundo en sencillos trazos y de reducir el paisaje a manchas de colores aguados. Es la misma sencillez formal que alcanza su arquitectura tras un depurado proceso de decantación de las ideas; la misma sencillez constructiva que reside en el uso correcto de los materiales que empleaban los antiguos carpinteros vikingos; la misma que emana de los barcos previamente dibujados.

Las acuarelas de Fehn también ponen de manifiesto el acervo cultural que le acompaña. El uso de técnicas propias de Henri Matisse y los intereses compartidos con Yves Klein, se suman a los argumentos pictóricos que vinculan Romanticismo y Expresionismo Abstracto, situados en la estela de sus propios intereses culturales.

De igual modo, la insistencia obsesiva en los mismos temas convierte su pintura en un instrumento de verificación cotidiana del espacio del mundo. La acción recíproca entre el hombre, el artificio y la naturaleza, es decir, entre bañistas, veleros y horizonte, condensa sus verdaderas inquietudes. Si los bañistas le aportan la conciencia de la interacción del cuerpo con la materia y el espacio, en el barco vislumbra la

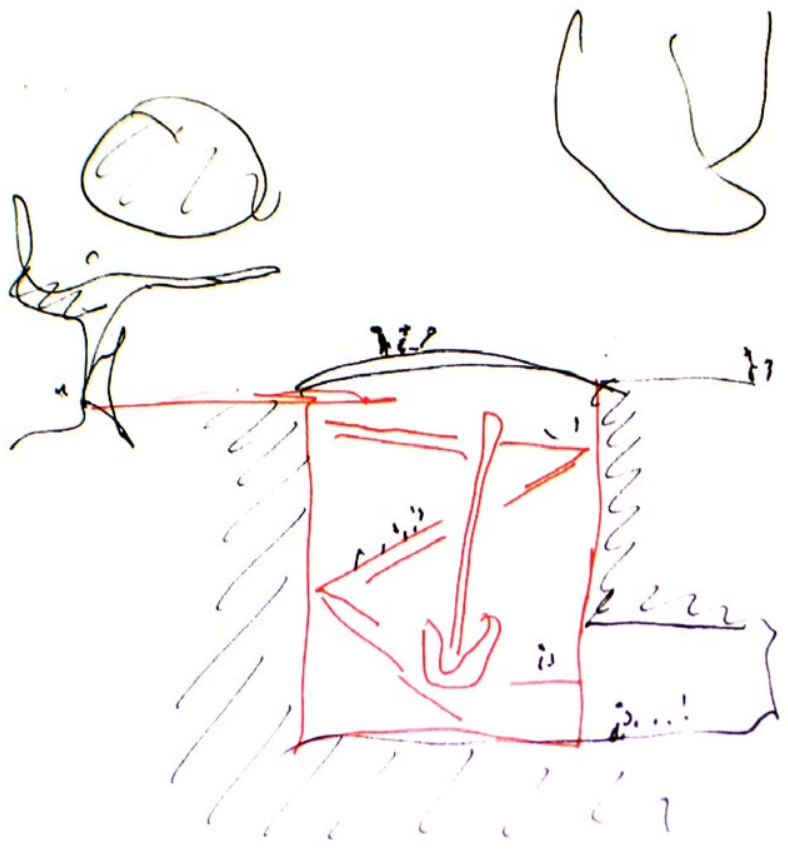

10. Sverre Fehn, croquis de El Museo Wasa (sin fechar) (Fuentes: Museo Nacional de Arte, Arquitectura y Diseño de Oslo. Foto de Iván I. Rincón Borrego)

relación de las creaciones humanas con el paisaje, codificado éste en la abstracción de la línea del horizonte.

La sensibilidad de Sverre Fehn por los vínculos que se establecen entre artificio y naturaleza, entre barco y horizonte, arquitectura y lugar, procede de sus acuarelas de Hvasser. Dicho binomio representa el catalizador de su proceso creativo, la línea argumental que conecta sus acuarelas con el alfabeto de símbolos y seres de sus ideogramas. Barcos y horizontes representan en sus acuarelas el gesto inicial, la paráfrasis gráfica que articula sus ideas y muchos de sus proyectos como los de Røros, Honningsvåg y Estocolmo.

La isla de Hvasser simboliza para él un pequeño cofre de memorias. Al regresar de sus jornadas de dibujo, Sverre Fehn solía decir que si un barco de velas rojas había alcanzado el horizonte, ese era un buen día para pintarlo, lo recuerda entrañablemente Per Olaf Fjeld (Fjeld, 2009: 22). Esa mañana, tan sólo por un instante, los enigmas de la mirada se tornaban resueltos y sus manos hábiles lo interpretaban en sencillos trazos. A continuación, será su memoria la que integre tal experiencia en el almanaque de su obra. 


\section{Notas}

1 Pese al impacto internacional de ambos pabellones, su repercusión se traduce en un buen número de contactos internacionales que sin embargo no duran mucho. Así lo recuerda junto a Per Olaf Fjeld: «Después de terminar el Pabellón de Venecia mantuve los contactos con Finlandia y Helsinki. Desde un punto de vista internacional, me salvaron. Christian [Norberg Schulz] me decía que tenía que pensar en hacer otro edificio como ese. Blomstedt y Pietilä fueron muy importantes para mí; el finés siempre me apoyó y fue un amigo fiel. Los CIAM me borraron de sus listas, y ya no fue tan fácil seguir vinculado a ellos" (Fjeld, 2009: 61).

2 La construcción del Centro Cívico en Bøler obtuvo un rechazo frontal por los habitantes de dicha comunidad. El caso de la Escuela en Skådalen resultó, si cabe, aún más lacerante pues las críticas fueron feroces. En diciembre de 1975 los periódicos de mayor tirada de Oslo denominaban el proyecto «infierno de hormigón", algo que se terminó convirtiendo en un ataque al propio Fehn.

3 Testimonio ratificado por Eva Madshus al autor del presente artículo el 7 de marzo de 2008 durante la inauguración de la muestra Architect Sverre Fehn. Intuition-Reflection-Construction organizada por el Museo Nacional Noruego de Arte, Arquitectura y Diseño de Oslo.

4 Durante la conferencia «The Skin, the Cut and the Bandage» que Sverre Fehn imparte en el MIT de Boston el 12 de abril de 1994 hace referencia explícita a su interés por el Land Art a través de la figura de Hannsjörg Voth, cuya obra Viaje al Mar de 1978 le obsesionaba durante el proyecto del Museo de los Glaciares. De la relación de la obra de Sverre Fehn con esta corriente artística véase «The Skin, the Cut, the Bandage. Legado y crítica en Sverre Fehn» (Rincón, 2014: 980).

5 La documentación gráfica más divulgada de Fehn son croquis procedentes de sus cuadernos A5. Los blocks contienen, además de pequeños bocetos de proyecto, un mantra gráfico de fábulas e ideogramas que relacionan las ideas que nutren su arquitectura. Realizados mayormente a tinta, se acompañan de escuetas palabras. Éste ha sido el material de estudio más habitual para explicar su personal universo. En los últimos años diversas tesis doctorales, RINCÓN BORREGO, Iván I. (2010), Sverre Fehn: la forma natural de construir, Tesis doctoral, Universidad de Valladolid y LÓPEZ COTELO, Borja (2013), Sverre Fehn desde el dibujo, Tesis doctoral, Universidad de A Coruña, y publicaciones, LÓPEZ DE LA CRUZ, Juan José; LÓPEZ PELÁEZ, José Manuel (2014), El dibujo del mundo. Sverre Fehn, Lampreave, han profundizado en la importancia de los croquis de Sverre Fehn para la compresión de su arquitectura.

6 El laberinto, fechado en 1988, y La Tierra como gran museo, recogido en la revista Byggekunst en 1982, son dos de las relatos más elocuentes dibujados por Sverre Fehn. En el primero, relata la capacidad simbólica que tiene la arquitectura de convertir el mundo en un gran laberinto a través de la interpretación heterodoxa que hace de la Villa Almerico de Andrea Palladio, a la luz de la obra de Jorge Luis Borges y de Antoine de Saint-Exupéry. Ver «El Laberinto, espacio simbólico en la arquitectura de Sverre Fehn» (Rincón, 2014: 175). En el segundo: «La Tierra constituye un gran museo en sí misma. En su corteza se hallan artefactos preservados por el mar y la arena cuyo viaje a la eternidad resulta tan lento que en sus restos aún se puede encontrar el rastro que originó su cultura [...] Las historias labradas en los muros y en los propios objetos han permanecido ocultas por la oscuridad, siendo conocidas sólo por la Tierra misma" (Fehn, 1985: 10) palabras que acompañan el dibujo de una Tierra en cuya superficie se encuentran varados edificios que van desde las pirámides de Egipto, hasta sus propios museos como el Museo Wasa (1982) o la Galería Verdens Ende (1988).

7 La orografía y el paisaje de Hvasser son muy característicos. La isla es un promontorio granítico pulido y resquebrajado por la acción conjunta de los glaciares y el mar, con una intensa actividad pesquera.

8 «Estoy casado con una intérprete y algunos de mis mejores amigos trabajan en la música y el arte» (Fehn, 1997: 211).

9 Charles Moore y Kent Bloomer comparan brillantemente la experiencia de la arquitectura con el mundo del ballet en Cuerpo, memoria y arquitectura: «los bailarines hablan de lo que es "sentir el espacio". Ese aire a través del cual la mayoría de nosotros mira para detenerse en los objetos sólidos, es para el bailarín una "materia" real (...). Así, el movimiento deja de ser un conjunto de acciones para convertirse en una interacción organizada y profundamente sentida con la materia positiva del espacio» (Bloomer y Moore, 1982: 70).

10 Según Per Olaf Fjeld: «Amigos y estudiantes recuerdan verle cada mañana temprano, con el bañador, la toalla y el cuaderno de dibujo colgado a la espalda montar en su bicicleta y pedalear a lo largo del camino de grava hacia la playa, las rocas y las gélidas aguas» (Fjeld, 2009: 21).

11 Traducido como La poética de la línea recta contiene obras tan significativas como el Museo Arzobispal de Hamar, El Museo de los Glaciares o su propuesta para la Capilla del Cabo Norte, así como todos sus proyectos de viviendas. Igualmente recoge los textos más relevantes que había realizado; La Arquitectura primitiva de Marruecos; ¿Cómo nacen nuestras dimensiones?; El sueño de las grandes construcciones y La danza alrededor de las cosas muertas.

12 El Poema del ángulo recto, publicado en 1955 en las Éditions Verve, constituye la obra de síntesis y recapitulación del pensamiento y las ideas de Le Corbusier en torno a la creación artística y arquitectónica. Sverre Fehn acudió insistentemente al estudio de Le Corbusier en el número 35 de la rue de Sèvres en los años previos a la publicación de El Poema del ángulo recto durante su estancia en París de 1953 a 1954.

13 Son muchos los artistas que pudieron influir en las acuarelas de Fehn y a buen seguro muchos de ellos nunca saldrán a la luz. No obstante, resulta sintomático apreciar cómo su interés por el horizonte es compartido por amigos arquitectos y compañeros de generación con los que prácticamente ya había perdido todo contacto en los años 70. Ese es el caso de Jørn Utzon y el conocido croquis del horizonte atrapado entre el suelo y las nubes que el arquitecto danés realiza en Hawai para la Iglesia de Bagsværd de 1973-76. La profundidad del paisaje y el peso etéreo de las nubes recuerdan la obra de Johan Christian Dahl, imagen que le proporciona al interior del edificio un carácter evanescente y luminoso propio de los cúmulos dibujados.

14 Las iglesias stave noruegas, construidas exclusivamente con madera, no hubieran podido realizarse sin la habilidad armadora de los carpinteros vikingos. Las concebían exactamente igual que un barco y sus detalles se identifican con los mismos términos navales. Igual que el casco de una embarcación debe ser autoportante porque carece de soportes externos, las iglesias stave se plantean como unidades estructurales autónomas, apenas apoyadas en el terreno. Esto se lleva a cabo mediante un esqueleto de pórticos arriostrados en todas las direcciones, sobre los que después se cerraba el interior mediante tablones y tejas de madera. Acerca de la tradición naval y constructiva vikinga consultar (Kavli, 1958: 16) y (Bugge y Norberg Schulz, 1990: 31).

15 Tanto es así que su primer proyecto de vivienda la casa Schreiner (1959-1963) lo ejecuta un carpintero especializado en la construcción naval: «Fue un constructor de barcos el que hizo la casa y fue perfecta; nunca he visto una técnica igual» (Fehn, 1997: 203). Tan impresionado queda Fehn por este hecho que vuelve a recurrir a él para la construcción de la casa Bodtker I (1961-65), su siguiente obra en Oslo, reflejándose de algún modo en el espejo de aquellos constructores vikingos que en el fondo admira.

16 Son diversos estudios que se han referido al barco como modelo en la arquitectura de Sverre Fehn, si bien destacan dos capítulos de sendos autores, RINCÓN BORREGO, I. (2010), «Huellas de un barco a la deriva» en Sverre Fehn: la forma natural de construir, Tesis doctoral, Universidad de Valladolid y LÓPEZ DE LA CRUZ, J. (2014), «El Drakkar y el granero» en El dibujo del mundo. Sverre Fehn, Lampreave. 
17 Noruega recupera la memoria de su herencia naval vikinga a partir de 1867, tras el descubrimiento del Tune, un navío encontrado en Østfold. Poco después, en 1880, fue descubierto el Gokstad en Sandefjord y en 1904 el Oseberg cerca de Tønsberg, la población donde Fehn pasó la mayor parte de su infancia. Finalmente en 1913, Arnstein Arneberg proyecta el actual Museo de los Barcos Vikingos donde se albergan los tres pecios, uno de los museos más vitados de toda Noruega.

18 De nuevo, durante el proceso de dimensionar y ajustar cada pieza de la iglesia, Fehn se halla a sí mismo como quien emplea la cuidadosa técnica con que se acoplan las partes de un bote. Vuelve a poner el acento en el carácter estructural de la forma: «la construcción de un barco Vikingo es un conjunto proporcionado de partes ensambladas con una precisión que se fundamenta en el entendimiento de las dinámicas del mar» (Fjeld, 2009:142).

19 El Wasa se descubre hundido en las cercanías del puerto de Estocolmo en 1961. El navío, mandado construir por Gustavo II Adolfo de Suecia entre 1626 y 1628. Estaba llamado a ser el buque insignia de la monarquía sueca, orgullo de su armada, pero supuso uno de sus mayores fracasos. Se trataba del mayor navío de guerra del momento. Armado con 64 piezas de artillería es botado el 10 de agosto de 1628 sin haber pasado las pruebas de estabilidad y termina naufragando a las pocas horas de su botadura debido a la desproporción entre la altura y la manga, que conseguían un centro de gravedad demasiado alto.

20 Según explica el autor, «la idea era no tocar demasiado la nave -que se hallaba enterrada en el lecho marino- y para ello decidimos recurrir a un dique seco que la mantuviera en la misma posición en que fue encontrada, a treinta metros en el subsuelo» (Fehn, 1994: 20).

21 La propuesta del Museo Wasa de Fehn ha sido comparada con obras como la Basílica de la Paz y el Perdón (1948) de Le Corbusier o el proyecto no construido de Jørn Utzon para el museo dedicado al artista danés Asger Jorn en Silkeborg (1969), proyectos ambos que Sverre Fehn conocía. Sin entrar en mayores consideraciones, diversos estudios han argumentado una «reinterpretación poética» directa en ellos, especialmente respecto al segundo, si bien hay notables argumentos que los diferencian. Véase (Rincón, 2010: 526).

\section{Bibliografía}

BLOOMER, Kent y MOORE, Charles W. (1982), Cuerpo, memoria y arquitectura, Herman Blume, Madrid.

BUGGE, Gunnar y NORBERG SCHULZ, Christian (1990), Stav Og Laft, Norsk, Arkiteturforlag, Oslo.

DREW, Philip (1973), Tercera generación: la significación cambiante de la arquitectura, Gustavo Gili, Barcelona.

FEHN, Sverre (1985), «Three museums», AA Files. Annals of the architectural association School of Architecture, n. ${ }^{\circ} 9$, p. 10.

FEHN, Sverre y FJELD, Per Olaf (1988), «Has a Doll Life?», Perspecta: The Yale Architectural Journal, n. ${ }^{24}$, pp. 40-49.

FEHN, Sverre (1992), «The Dream of Great Construction», en NORRI, Marja-Riitta y KÄRKKÄINEL, Maija (ed.), The Poetry of Straight Line:

Five Masters of the North, Museum of Finnish Architecture, Helsinki, p. 34.

-(1992), «An Architectural Autobiography», en NORRI, Marja-Riitta y KÄRKKÄINEL, Maija (ed.), The Poetry of Straight Line: Five Masters of the North, Museum of Finnish Architecture, Helsinki, p. 45.

- (1994), «The Skin, the Cut \& the Bandage», en ANDERSON, Stanford (ed.), The Pietro Belluschi Lectures, The MIT Press, Boston.

- (1997), «Sverre Fehn. Proyectos de Viviendas», en MELGAREJO, María (ed.), Nuevos modos de habitar, Colegio Oficial de Arquitectos de la Comunidad Valenciana, Valencia.

FJELD, Per Olaf (2008), «Sverre Fehn and the Architectural Refinement of Spatial Instinct», en YVENES, Marianne y MADSHUS, Eva (ed.),

Architect Sverre Fehn: Intuition, Reflection, Construction, The National Museum of Art, Architecture and Design, Oslo, p. 34.

- (2009), Sverre Fehn: the Pattern of Thoughts, The Monacelli Press, New York.

KAVLI, Guthorm (1958), Norwegian Architecture. Past and Present, Dreyers Forlag, Oslo.

KNUTSEN, Knut (2008), «People in Focus», en ASGAARD ANDERSEN, Michael (ed.), Nordic Architects Write. A Documentary Anthology.

Routledge, New York, pp. 249-252.

LÓPEZ COTELO, Borja (2013), Sverre Fehn desde el dibujo, Tesis doctoral, Universidad de A Coruña.

LÓPEZ DE LA CRUZ, Juan José; LÓPEZ PELÁEZ, José Manuel (2014), El dibujo del mundo. Sverre Fehn, Lampreave.

LOGE, Øystein (1991), Deformasjon/Deformation. Disintegratong the Classical Concept of Nature in Norwegian Landscape Painting, Dreyers Forlag, Oslo.

MADSHUS, Eva (2008), «Architect Sverre Fehn. Intuition-Reflection-Construction», en YVENES, Marianne y MADSHUS, Eva (ed.), Architect

Sverre Fehn: Intuition, Reflection, Construction, The National Museum of Art, Architecture and Design, Oslo.

NORBERG SCHULZ, Christian y POSTIGLIONE, Gennaro (1997), Sverre Fehn: Works, Projects, Writings, 1949-1996, The Monacelli Press, Milan.

RINCÓN BORREGO, Iván I. (2010), Sverre Fehn: la forma natural de construir, Tesis doctoral, Universidad de Valladolid. 
RINCÓN BORREGO, Iván I (2014), «The Skin, the Cut, the Bandage. Legado y crítica en Sverre Fehn», en SORIANO, Federico (dir.), Critic|all I. International Conference on Architectural Design \& Criticism, Criticlall Press, Madrid, pp. 978-986.

- (2014), «El Laberinto, espacio simbólico en la arquitectura de Sverre Fehn», en VILLALOBOS, Daniel; RINCÓN, Iván I. y PÉREZ, Sara (ed.), Arquitectura, símbolo y modernidad, Real Embajada de Noruega en España y Dpto. de Teoría de la Arquitectura y Proyectos Arquitectónicos Universidad de Valladolid, Valladolid, 2014, pp. 175-190.

ROSEMBLUM, Robert (1993), La pintura moderna y la tradición del Romanticismo nórdico. De Friedrich a Rothko, Alianza, Madrid.

STEEN MOLLER, Henrik (1997), «Sverre Fehn-An Interview with the Norwegian architect», Living Architecture, n. ${ }^{\circ} 15$, pp. $211-213$. 